\title{
Precursors of Reading Difficulties in Czech and Slovak Children At-Risk of Dyslexia
}

\begin{tabular}{|r|l|}
\hline Journal: & Dyslexia \\
\hline Manuscript ID & DYS-15-07-RA-0016.R1 \\
\hline Wiley - Manuscript type: & Research Article \\
\hline Keywords: & Dyslexia, Children, Development, Language \\
\hline Abstract: & $\begin{array}{l}\text { Children with preschool language difficulties are at high-risk of literacy } \\
\text { problems; however the nature of the relationship between delayed } \\
\text { language development and dyslexia is not understood. 308 Slovak and } \\
\text { Czech children were recruited into three groups: family-risk of dyslexia, } \\
\text { speech/language difficulties and controls, and were assessed three times } \\
\text { from kindergarten until Grade 1. There was a two-fold increase in } \\
\text { probability of reading problems in each risk group. Precursors of 'dyslexia' } \\
\text { included difficulties in oral language and code-related skills (phoneme } \\
\text { awareness, letter-knowledge and RAN); poor performance in phonological } \\
\text { memory and vocabulary was observed in both affected and unaffected } \\
\text { high-risk peers. A two-group latent variable path-model shows that early } \\
\text { language skills predict code-related skills, which in turn predict literacy } \\
\text { skills. Findings suggest that dyslexia in Slavic languages has its origins in } \\
\text { early language deficits and children who succumb to reading problems } \\
\text { show impaired code-related skills before the onset of formal reading } \\
\text { instruction. }\end{array}$ \\
\hline \hline
\end{tabular}


Precursors of Reading Difficulties in Czech and Slovak Children At-Risk of Dyslexia

\section{Word count:}

150 Abstract

6082 Manuscript

969 References

849 Tables and figures

298 Supporting Information 


\begin{abstract}
Children with preschool language difficulties are at high-risk of literacy problems; however the nature of the relationship between delayed language development and dyslexia is not understood. 308 Slovak and Czech children were recruited into three groups: family-risk of dyslexia, speech/language difficulties and controls, and were assessed three times from kindergarten until Grade 1. There was a two-fold increase in probability of reading problems in each risk group. Precursors of 'dyslexia' included difficulties in oral language and code-related skills (phoneme awareness, letter-knowledge and RAN); poor performance in phonological memory and vocabulary was observed in both affected and unaffected high-risk peers. A two-group latent variable path-model shows that early language skills predict code-related skills, which in turn predict literacy skills. Findings suggest that dyslexia in Slavic languages has its origins in early language deficits and children who succumb to reading problems show impaired code-related skills before the onset of formal reading instruction.
\end{abstract}

Keywords: Risk of Dyslexia; Language Impairment; Phonological Deficit; Precursors of literacy skills; Endophenotypes; Slavic Languages 


\section{Precursors of Reading Difficulties in Czech and Slovak children at-risk of dyslexia}

Dyslexia is a neurodevelopmental disorder characterized by difficulties in learning to read (decode) and to spell. However, 'diagnosis' is controversial because there is no clear cut-off between 'dyslexic' and 'normal' reading (Snowling \& Hulme, 2012). One way of clarifying the nature of dyslexia is by seeking explanations of its underlying causes early in development, prior to reading instruction, and tracing its developmental trajectory. Studies which follow children at high-risk of dyslexia from the preschool years are important in this regard; these include children born to families with a history of reading difficulties and children with slow speech and language development.

The predominant causal hypothesis of dyslexia posits that an underlying phonological deficit affects the acquisition of literacy skills (e.g., Vellutino, Fletcher, Snowling, \& Scanlon, 2004). Indeed, phoneme awareness together with letter knowledge and rapid automatized naming (RAN) - often referred to as 'code related skills' - are robust predictors of individual differences in reading development (and dyslexia) across alphabetic orthographies (Caravolas et al., 2012; Moll et al., 2014; Ziegler et al., 2010). However, studies of children at family-risk of dyslexia can highlight risk factors which predate code-related skills. Contrary to the notion that dyslexia is caused by a specific phonological deficit, such studies suggest that the phonological deficit is not sufficient to explain dyslexia (Snowling \& Melby-Lervag, 2016, for a review). First, many children who go on to develop dyslexia show slow language development through the preschool years (e.g. Scarborough, 1990;

Puolakanaho et al., 2007); their difficulties are not specifically in phonological language 
processes but also encompass vocabulary and grammatical development (e.g., Carroll, Mundy \& Cunningham, 2014). Second, children at family risk of dyslexia who do not succumb to reading problems also experience phonological difficulties, albeit less severe (Moll, Loff, \& Snowling, 2013; Pennington \& Lefly, 2011; Snowling, Gallagher \& Frith, 2003). Relatedly, children with speech and language difficulties often develop dyslexia (Pennington \& Bishop, 2009). Thus, the inter-relationships between phonological and broader language skills in the etiology of dyslexia deserve further investigation.

One hypothesis is that slow language development delays the acquisition of the code-related skills that are proximal to dyslexia. Findings from two family-risk studies are in line with this view (Snowling et al., 2003; Torppa and colleagues, 2007; 2010). In both samples, there were strong predictive links from early language skills to reading outcomes via letter knowledge and phonological awareness. Torppa (2007) reported two additional mediators, rapid naming and morphology; these predicted reading in children learning to read in Finnish and may do so in other languages.

In the present paper, we report findings from a study of children at high risk of dyslexia speaking Slavic languages, viz Czech and Slovak. Whereas English has inconsistent grapheme-phoneme-correspondences (GPCs) and is morphologically simple, the Czech and Slovak orthographies contain highly consistent GPCs - Czech uses diacritics to mark acute accent and Slovak to mark some long consonants. In Czech and Slovak $<\mathrm{ch}>$ is a digraph but is considered a single 'letter' in each; $<$ dž $>$ is a true digraph only in Slovak (not in Czech). Both languages are highly inflected with nouns and adjectives obligatorily marked for case, gender and number, while verbs are marked for person, number, tense and gender. Czech and Slovak are fusional which 
means a single grammatical morpheme frequently expresses different grammatical functions, e.g. gender, case and number. Whereas English content words can appear without inflections, in Czech and Slovak the lexical stem of nouns, adjectives and verbs cannot occur on its own without an inflectional suffix.

In the current study we recruited two groups of children into an 'at-risk' sample together with controls: children at family risk of dyslexia, and children with clinical concerns about their speech and language development. The main aim of the study was to identify preschool risk factors associated with dyslexia in these two Slavic languages. Following Caravolas et al. (2012), we predicted that reading problems in children learning to read would be associated with deficits in code-related skills from an early age (letter knowledge, phoneme awareness and RAN). Second, given that the languages are morphologically complex, we hypothesized that poor reading would be associated with poor grammatical skills. Finally, following Moll et al. (2013) who proposed that phoneme awareness and nonword repetition are endophenotypes of dyslexia (heritable risk factors), we predicted that, among children at family risk of dyslexia, we would find a continuum of phonological difficulties such that those who succumbed to reading problems would have poorer phonological skills than those who were classified as typical readers who, in turn, would do less well on these phonological tasks than controls.

\section{Method}

\section{Participants}

A total sample of 308 Slavic-speaking children (158 Slovak, 150 Czech) were recruited to the study from two centres, one in Prague and one in Bratislava, to participate in the (name deleted for review) study, a comparative longitudinal study of 
monolingual Czech- and Slovak-speaking children at high-risk of reading difficulties. Recruitment was via advertisements, referrals from speech therapists, and from dyslexia associations.

Following referral, children were assigned to one of three groups (1) the familyrisk (FR) group if they had a first-degree relative with dyslexia (parent or older sibling); (2) the group of children with speech and language difficulties (SLD) if there were clinical concerns regarding their oral language skills. These children either reached a research criterion for specific language impairment (SLI) of one standard deviation below the age-specific mean on two out of three language measures (Vocabulary, Receptive and Expressive Grammar) or fulfilled criteria for speech sound disorder (SSD), defined by pronouncing fewer than $80 \%$ of consonants correctly on a clinical test of articulation; (3) a control group without familial risk of dyslexia and with ageappropriate language skills.

Czech and Slovak are mutually intelligible Slavic languages (see Supporting Information Table A.1 for examples) with minimal linguistic differences (Mistrík, 1993) justifying combining data across the languages. Following recruitment, 308 families gave informed consent for their children to participate and were seen three times at intervals of one year: in kindergarten (T1), at the end of kindergarten prior to school entry (T2), and after one year of literacy instruction (T3). After T2, as is the practice in the Czech and Slovak Republics, 64 children with language delays and difficulties did not enter school but were kept behind to repeat a year in kindergarten (where they did not receive any formal literacy instruction). Supporting Information (Table A2) shows descriptive statistics for the longitudinal sample for comparison with the children held back in kindergarten on $\mathrm{T} 1$ measures of general cognitive ability and 
language and T2 measures of precursors to literacy (Letter knowledge, Phoneme Awareness and RAN). It can be seen that already at T2 the kindergarten group were having difficulty with all three code-related skills. At T3 they performed at floor on the literacy tests and hence were removed from the sample for analysis together with 43 children (23 Czech and 20 Slovak) for whom data were available only at T1 and T2 and children who were older than the rest of the sample, leaving only data that were missing at random $(<3 \%)$. There was no difference between the children in the longitudinal sample and those lost to sample owing to attrition between T2 and T3 in age (Means attrition versus longitudinal sample: 65.73 vs. $66.32 ; t<1, p=.416$ ) or Raven's IQ (Means: 16.38 vs. $17.57 ; t=1.51, p=.133$ ) at $\mathrm{T} 1$.

The final longitudinal sample comprised 198 children followed from 5 to 7 years, being those enrolled in school by T3; 38 children (22 boys) at family-risk (FR) of dyslexia, 60 children (42 boys) with clinical concern about speech-language development (of whom 17 (12 boys) had speech sound disorder) and a comparison group of 100 (44 boys) typically developing children with neither a family history of dyslexia nor concerns about speech and language development. Fig. 1 shows participant flow through the study from recruitment through T1, T2, and T3 according to language (Czech and Slovak), subgroup (TD, FR, and SLD), and whether or not the child was enrolled in school by T3.

\section{$<$ Insert Fig. 1 here $>$}

\section{Tests and Procedures}

Children were seen individually at home, in kindergarten/school or in a speech therapy clinic to administer an extensive battery of tests at approximately yearly time intervals (mean age at $\mathrm{T} 1=66.3 ; \mathrm{T} 2=76.9 ; \mathrm{T} 3=88.8$ months). In the absence of 
standardized tests, many of the language tasks were designed for the purpose of this study by adapting measures from an ongoing, parallel longitudinal study of children atrisk of dyslexia (see Nash, Gooch, Hulme, \& Snowling, 2013, for details); reading and related tasks were also taken from a battery developed by Caravolas et al. (2012) to investigate early literacy development in European languages. The test battery relevant to the current paper is described below.

T1 and T2 measures. All precursors were assessed at T1 and T2. An exception was nonverbal IQ which was only measured at T1. For non-standardized tests, reliabilities (Cronbach's Alpha) were calculated for each time point based on the current sample.

Non-verbal Ability. Two measures of non-verbal ability were used. RAVENS Coloured Matrices (Raven, 1965) is a multiple choice measure of fluid intelligence. For a series of test items, the child is asked to identify the missing element that completes the pattern. Scores for parts $\mathrm{A}, \mathrm{AB}$ and $\mathrm{B}$ are summed together as a total score. The Block design subtest of the Wechsler Preschool and Primary Scale of Intelligence (WPPSI; Wechsler, 2004) is a visual-spatial measure. Children are required to assemble a set of blocks to match a template.

Letter knowledge. Two measures of letter knowledge were used, letter naming and letter writing. In letter naming, children were presented large printed capital letters. Letters with low frequency were excluded $(<20 \%$ of the existing letters in the Slovak and Czech alphabet). At T1, any valid designation of letters - the sound or name - was accepted as a correct response. Letter writing required the children to write 15 graphemes (five vowels - a, e, i, o, u, and 10 consonants-- m, k, z, s, p, 1, d, b, v, ž) to dictation. The letter knowledge score is a composite of the percentage of correct 
responses in the letter naming and writing tasks. Cronbach's Alpha is .98 and .97 for Czech and Slovak at T1 and .98 for both languages at T2.

Phoneme Awareness. Two measures of phoneme awareness were used. The Phoneme isolation task requires children to identify the first or the last phoneme in a pseudoword. The 32 items were presented in four blocks of eight items each. In the first two blocks children were asked to identify the first phoneme (eight CVC and eight CCVC) and in the last two blocks they were asked to identify the last phoneme (eight CVC and eight CVCC). The test was discontinued after four consecutive errors in each of the first two blocks. Phoneme matching required the children to match a word either according to initial or final sounds (e.g. last phoneme: nos - pes or med). Words were presented as pictures. At T1 there were 12 items ( 7 initial and 5 final phonemes); at T2 there were 24 items (12 initial and 12 final phonemes). Cronbach's Alpha for phoneme awareness is .94 for T1 and .95 for T2.

$\boldsymbol{R A N}$ - objects and colours. Children were presented two sets of forty objects and colours and asked to name them as quickly as possible. The average time taken for a set and the number of errors made was measured. The number of errors made was constrained to a maximum of 10 . In order to rule out the possibility that long RTs are the consequence of getting stuck at a single item rather than generally slow naming, times were adjusted by bringing in outliers to within 2.5 SDs of the mean. The scores were then converted to a rate of items per second for analyses. Correlations between the two sets are .86 and .89 for RAN objects and .83 and .89 for RAN colours at T1 and T2, respectively.

Phonological memory. Two tests were used to measure phonological memory. In the word/pseudoword repetition test, children were asked to repeat 28 words and 28 
pseudowords varying in item length. The 28 words were high frequency familiar words selected from TEKOS I, TEKOS II (Kapalková, Slančová, Kesselová, \& Mikulajová, 2010) and Weslalex databases (Czech and Slovak; Kessler \& Caravolas, 2011). The one- to four-syllable words (six items each) and the four five-syllable words were presented in mixed order. The pseudowords were derived from these words by exchanging one phoneme per syllable. At T2, the sets of six one syllable pseudowords and words were dropped from the test, leaving 22 pseudowords and 22 words. In evaluating responses, phonological errors (as observed in a separate articulation test) were not penalized. Articulation errors were counted as errors with the following exceptions: sibilants (i.e., /s/ articulated as $/ \mathrm{f} /$ ) and mispronunciations of the sounds $/ \mathrm{r} /$ and $/ 1 /$ were not penalized, because these represent mispronunciations that are typical for Czech and Slovak children under 5-6 years. Cronbach's Alpha is .92 for T1 and .90 for $\mathrm{T} 2$.

The nonword repetition task required the child to repeat 20 phonotactically legal nonwords that did not resemble real words in either Czech or Slovak. Items consisted of one- to five- syllable nonwords (four items per condition); they were constructed using $\mathrm{CV}, \mathrm{CVC}$ and $\mathrm{CCV}$ syllables and their combinations. All phonemes were included, except those with very low frequencies. Repetitions were evaluated for correctness and the relevant measure was the number of correctly repeated nonwords. Similarly to the word/pseudoword repetition test, the one syllable words were removed from the test at T2, leaving 16 non-words. Again, neither phonological errors nor specific articulation errors (/s/, /r/, and /1/) were penalized. Cronbach's Alpha is .85 for T1 and .75 for T2.

The relevant measure for both repetition tasks used in the analysis was the percentage of correctly repeated items. 
Grammar. A grammatical test measuring receptive and expressive grammar was devised including 40 (T1) and 48 (T2) items, respectively. Receptive items were taken from a translated version of the Test of Reception of Grammar-2 (TROG-2; Bishop, 2003). At T1, the 16 receptive items included four blocks: embedded subject and embedded object sentences (e.g., the shoe that is red is in the box), passive sentences, and relative clauses. At T2, an additional two blocks were included: neither - nor (e.g., neither the girl nor the dog is sitting), and singular - plural, resulting in a total of 24 items. For each item children are asked to select the correct picture out of four that corresponds to the sentence spoken by the examiner.

The 24 expressive items required morphological awareness: children were presented incomplete sentences for completion assessing six different grammatical structures in three categories: Noun phrases (plural, genitive, and grammatical agreement), verbal phases (past tense and $3^{\text {rd }}$ person singular), and derivations of nouns from verbs. Note that Czech and Slovak are highly inflected languages in which nouns and adjectives are obligatorily marked for case, gender and number, and verbs are marked for person, number, tense and gender. For example, in the grammatical agreement subtest, the examiner presented a sentence in nominative case (this is a 'little spoon' - 'malá lyžička') and prompted the child to produce accusative case (what do you use to stir your tea? - 'malú lyžičku'). Cronbach's Alpha for the grammar test is .82 for $\mathrm{T} 1$ and .85 for $\mathrm{T} 2$.

Vocabulary. This measure is a translated version of the WPPSI (Wechsler, 2004) which tests the ability of children to define words. For picture items, the child names pictures that are displayed in a stimulus book. For verbal items, the child gives definitions for words that the examiner reads aloud. There are 25 items: five with 
images, 20 without a picture. The first seven items could be awarded one point, the remaining items were scored out of two points (maximum score $=43$ ).

\section{T3 outcome measures.}

Word list reading. Children are asked to read a list of 12 words as accurately and fluently as possible until they failed to read 4 consecutive words. A correct response was recorded when a word was read correctly and fluently. When the child read single phonemes without blending them together this was recorded as incorrect. The score is the number of words read correctly per second (Cronbach's Alpha $=.97$ ).

One minute reading test. Reading fluency was assessed using the word and pseudoword subtests from the One-minute reading test (Caravolas \& Volin, 2005). The child is asked to read as many words/pseudowords as possible in 60 seconds. A correct response means that the word was read correct and fluently. If the child read the word phoneme by phoneme without blending the sounds, this was considered as an error.

Data from the Word list reading and the One minute reading tests at $\mathrm{T} 3$ were combined to form a composite Decoding measure first standardizing using z-scoring and then summing. The variance was adjusted by dividing by the number of test items to create a standardized composite score.

Spelling. Children were asked to spell 14 single words that were dictated in a sentence frame. Items were taken from a standardized spelling test (Caravolas, Mikulajova, \& Vencelova, 2008) and were constructed to include orthographic markers, so that phoneme-grapheme transcription alone would not result in orthographically correct spellings. The test score was the number of orthographically correctly spelled words.

\section{Results}




\section{Data Screening and Preparation}

Preliminary data screening suggested the data from the Czech and Slovak samples could be combined. Correlations were slightly higher in the Czech compared to the Slovak sample, but the pattern of correlations was comparable between the two samples (see Supporting Information, Table A3 for correlations between main variables for the two samples); in addition, the results of an ANOVA comparing groups on the decoding composite indicated that performance at T3 was at a similar level in the two languages, $\mathrm{F}(2,195)=1.593, \mathrm{p}=.206$.

We first present analyses of the performance of the three groups of children (TD, FR, SLD) on language and reading-related tasks at T1 and T2 before reporting the outcomes of these children in decoding skills and the number of children from each group who were poor readers at $\mathrm{T} 3$. We next conduct retrospective analyses to investigate preschool differences between the poor readers and those who are typically developing, focusing on the isolation of risk factors in the early years. Finally we use path analysis to investigate the predictors of literacy (decoding and spelling) in the atrisk and typically developing control groups.

\section{Performance of TD, FR, and SLD children on language and reading-related tasks <Insert Table 1 here $>$}

Table 1 shows the performance of the three groups of children (TD, FR, SLD) at T1 and T2 across the test battery, together with statistical group comparisons. Age correlated with NVIQ and RAN at T2 and was controlled using ANCOVA. As expected, the two risk groups performed less well than the TD group on most measures. There was some variability across measures but in general there was a stepwise pattern with the TD group performing better than the FR group which in turn performed better 
than the SLD group. Exceptions were for three language measures: W/NW Recall, Nonword Repetition and Vocabulary at T1 where the FR and SLD groups performed similarly, and the FR group gained the highest letter knowledge score at T1. Overall group differences were not significant for NVIQ, Phoneme Awareness, letter knowledge or RAN at $\mathrm{T} 1$ or in grammar at $\mathrm{T} 1$ and $\mathrm{T} 2$.

Given the known stability of reading skills, particularly in consistent orthographies (e.g., Landerl \& Wimmer, 2008; Lervag \& Hulme, 2009), we operationalized a definition of reading difficulties as a score on the composite Decoding measure at least 1.5 SDs below the mean of the TD group (mean=102.02; $\mathrm{SD}=12.91$ ) after one year of reading instruction. While it is not possible to ascertain the prevalence of dyslexia from such data, we expected these children to have ongoing literacy difficulties.

The mean scores of each group together with the percentage of children from each of the TD, FR, and SLD groups whose reading skills fall below the cut off are shown in Table 2. Overall group differences in decoding skill were small and not significant $(F(2,195)=1.599, p=.21)$. There were more children with reading problems in the two risk groups $(\mathrm{SLD}=20 \%$ and $\mathrm{FR}=22 \%)$ than the control group (13\%); however, differences in frequencies between children at risk $(\mathrm{FR}+\mathrm{SLD})$ and TD children did not reach significance, $z=-1.462, p=.07$ (one-sided).

<Insert Table 2 here>

\section{Risk Factors for Reading Difficulties: preschool differences between poor readers and typically developing controls}

In order to investigate risk factors for poor reading (endophenotypes of dyslexia), we regrouped children according to their reading status based on the $1.5 \mathrm{SD}$ 
cut-off criterion reported above. Given small numbers, for these analyses, children at family-risk and children with preschool speech and language difficulties (SLD) were treated together as 'at-risk' of dyslexia. This procedure yielded four groups: TD normal reader (TD- Normal reader: Mean decoding composite $=104.8, \mathrm{SD}=11.6 ; N=87$ ), TD poor reader (TD-Poor reader: Mean decoding composite $=83.8, \mathrm{SD}=2.6 ; N=13$ ), Atrisk normal reader (AR-Normal reader: Mean decoding composite $=103.9, \mathrm{SD}=13.1$; $N=78$ ), and At-risk poor reader (AR-Poor reader: Mean decoding composite $=82.0$, $\mathrm{SD}=4.5 ; N=20)$.

Three comparisons can be made based on this classification: First, in order to investigate the risk factors which are putative causes of dyslexia, retrospective analyses were conducted to compare the pre-school performance of the children from the at-risk groups who were classified as having reading difficulties (AR-Poor reader) with that of typically developing controls (TD-Normal reader). Secondly, to investigate putative endophenotypes of dyslexia (i.e. factors that are associated with the risk of dyslexia), the at-risk children classified as normal readers (AR-Normal reader) were compared with the TD controls and AR-Poor reader groups. Finally, the AR-Poor reader group was compared with the TD-Poor reader group; this comparison tells us whether the risk factors for reading problems differ according to whether the child is drawn from the typical population or whether the child is known to be at high risk of dyslexia by virtue of having a first degree relative with dyslexia or having preschool speech-language difficulty.

Table 3 shows the performance of children across the cognitive measures at T1 and $\mathrm{T} 2$, grouped according to $\mathrm{T} 3$ outcome and controlling for age as a covariate. We analysed these data in a series of one way ANCOVAs followed by post-hoc tests to 
compare means using Bonferroni. Bonferroni corrections are used to account for multiple tests, in this case, accepting statistical significance at $p<.0063$.

$<$ Insert Table 3 here $>$

We first considered the hypothesis that the pre-school performance of children from the at-risk groups classified later as having reading problems (AR-Poor reader) is significantly poorer than that of typically developing controls (TD-Normal reader) in code related skills. There were large and statistically significant differences between the AR-Poor reader and TD-Normal reader groups for letter-sound knowledge, phoneme awareness, and RAN at T1 (Cohen's $d s=1.18-1.39)$ and again for all three code-related skills at T2 $(d s=1.13-1.73)$. The two groups did not differ in grammatical skills at T1 $(d=0.87)$, but did at T2 $(d=0.89)$.

We next considered the pattern of group differences for two putative endophenotypes of dyslexia, word/pseudoword recall and non-word repetition. At both time points, the AR-Poor reader group was impaired $(d s=1.25-2.01)$, and so was the AR-Normal reader group who performed like them and significantly less well than the TD-Normal reader group $(d \mathrm{~s}=0.69-1.10)$. A similar pattern was observed for vocabulary, especially at $\mathrm{T} 1(d \mathrm{~s}=1.29$ for the AR-Poor reader group and 0.76 for the AR-Normal reader group).

Finally, we compared the AR-Poor reader group with the TD-Poor reader group. The groups did not differ significantly on any T1 or T2 measure. However, there was a trend for the AR-Poor reader group to be more impaired than the TD-Poor reader group $(d \mathrm{~s}=0.42-1.39$ at $\mathrm{T} 1$ and $0.26-1.46$ at $\mathrm{T} 2)$, especially for two putative endophenotype measures, word/pseudoword recall and non-word repetition $(d \mathrm{~s}=0.86-$ $1.46)$. 
Further, mindful of the small sample sizes involved, we tentatively compared the AR-Poor readers with a family history of dyslexia (FR) with those with a developmental history of language problems (SLD). The FR group were more impaired on tests of phoneme awareness and RAN than the SLD group with large effect sizes, but not in letter knowledge or reading. In contrast, the SLD group were more impaired in grammar.

\section{Predictors of reading and spelling in at-risk and typically developing groups}

Although the analyses of preschool differences between children who go on to be classified as poor readers and controls can elucidate the precursors of dyslexia, firmer conclusions regarding causal relationships can be drawn from longitudinal data which treat literacy as a continuous measure and analyse the developmental pathways from preschool through the antecedents of reading and spelling, namely phoneme awareness, letter knowledge and RAN. As an initial step to assessing the predictors of decoding at T3, we tested a single group model in which measures of letter knowledge, phoneme awareness and RAN at T2 mediated the effects of non-verbal ability, preschool language (receptive and expressive grammar and vocabulary) and phonological skills (word/pseudoword recall and nonword repetition) at T1. In this model neither the effects of non-verbal ability nor phonological skills at T1 on T2 measures was significant; these variables were therefore dropped from further iterations of the modelling. A similar pattern emerged when spelling was the outcome measure.

Next, a two-group latent variable path model was constructed in which variations in preschool language at T1 (receptive and expressive grammar and vocabulary) predicted the three $\mathrm{T} 2$ foundation skills of phoneme awareness (phoneme isolation and phoneme matching), letter knowledge (letter naming and letter writing) 
and RAN (objects and colours) and in turn these predicted T3 decoding (defined by word list reading and the one-minute reading tests) and spelling (defined by spelling words orthographically correct). We used this model to assess both the direct and indirect effects of language at T1 on decoding and spelling at T3, separately for the atrisk and TD groups. This model encountered some issues due to collinearity between phoneme awareness and letter knowledge at T2. To overcome this problem, the proposed model merged phoneme awareness and letter knowledge $(r=.84)$ into a single factor. The final two-group model (Fig. 2) shows T1 language to T2 foundation skills, then T2 foundation skills to T3 decoding and spelling. Unstandardized path weights were constrained to be equal between the two groups. The model gives a reasonably good fit to the data $\left(\chi^{2}(113)=155.447, p<.005, C F I=0.973, R M S E A=\right.$ $0.062(90 \%$ CI $0.035-0.084), S R M R=0.082)$.

<Insert Fig. 2 here $>$

Both paths from T1 language to T2 foundation skills were significant in both groups: T1 Language predicted RAN and phoneme awareness/letter knowledge at T2 to a similar degree in typically developing and at-risk groups. The influence of language was strongest on phoneme awareness/letter knowledge and weaker on RAN.

For both groups, T2 measures of RAN and phoneme awareness/letter knowledge are significant predictors of decoding at T3, the influence of phoneme awareness/letter knowledge being stronger than the influence of RAN. However, only T2 phoneme awareness/letter knowledge and not RAN is a significant predictor of spelling at T3.

In this model there are three indirect paths relating early variation in language skills at T1 to variation in decoding and spelling skills at T3. All indirect paths are 
statistically reliable in both groups, confirmed using bias corrected bootstrapped confidence intervals:

(1) Language through phoneme awareness/letter knowledge to decoding (TD standardized effect $=0.43 ; p=.001 ;$ AR standardized effect $=0.41 ; p=<.001) ;(2)$ Language through RAN to decoding (TD standardized effect $=0.102 ; p=.011 ; \mathrm{AR}$ standardized effect $=0.096 ; p=.017) ;(3)$ Language through phoneme awareness/letter knowledge to spelling (TD standardized effect $=0.335 ; p<.001 ;$ AR standardized effect $=0.279 ; p=<.001)$

The model shows complete mediation. Thus, the indirect effects of language at T1 through foundational skills at T2 accounted for all the variance in decoding and spelling at $\mathrm{T} 3$ for both groups leaving no statistically reliable direct effect of language on early literacy skills.

\section{Discussion}

This study followed the literacy development from preschool to one year after formal reading instruction of children learning to read in Czech and Slovak. These two Slavic languages have the same roots and are mutually intelligible; each has a relatively consistent orthography and the pattern of literacy development has been shown to be similar in the two languages (e.g., Caravolas, et al., 2012). We selected children based on family and developmental history to be at at-risk of dyslexia either because they have a first degree affected relative (family-risk) or because they had a preschool speech or language difficulty (SLD) causing clinical concern and compared them with children with no such history, assumed to be typically developing. After one year in school we classified children into 'poor reader' or 'normal reader' groups based on a measure of decoding skills. 
As expected, we found an increased probability of poor reading in the at-risk groups. While our estimate of $12.9 \%$ of typically developing children who were poor readers is broadly in line with that reported for controls by comparable studies of children at family-risk of dyslexia, the estimates of $20-22 \%$ for the at-risk groups are lower than the rates reported previously for children at family-risk ( $45 \%$ on average). It needs to be borne in mind that our longitudinal sample, while including children with concerns about speech-language development, excluded children who were held back in preschool because of oral language difficulties and it is reasonable to expect such language problems to compromise literacy development once formal teaching begins (Hulme, Nash, Gooch, Lervag, \& Snowling, 2015; Storch \& Whitehurst, 2002). To provide an estimate of the likely outcomes for the children who were held back, we used a regression model in which we predicted $\mathrm{T} 3$ reading outcomes from code related skills at T2 (measures of letter knowledge, RAN, and phoneme awareness) based on the final sample which went to school. We then used this model to predict the expected outcomes of the kindergarten group (that is if had they gone on to receive reading instruction). Using the cut-off of $-1.5 \mathrm{SD}$ below the mean of the school group for Decoding skills, we estimate that $36 \%$ of the kindergarten children would have become poor readers. Thus, the estimate of $20-22 \%$ reading difficulties in the at-risk groups reported in the current study is likely to underestimate the prevalence rate of reading difficulties in children at risk of dyslexia given that children with language difficulties are often held back in kindergarten and were there not included in the current study.

Turning to the antecedents of dyslexia, the results confirmed our second hypothesis that the proximal predictors of poor fluency in decoding in children learning to read in Czech and Slovak are deficits in phoneme awareness, letter knowledge, and 
RAN. These deficits were not associated with significant differences in general cognitive ability as measured by NVIQ. It is also noteworthy that for phoneme awareness, letter knowledge, and RAN at both time points, there was a step-pattern with the performance of the at-risk group who did not succumb to reading problems (ARNormal reader) falling between the AR-Poor reader and TD-Normal reader groups. This finding suggests that both risk groups were less 'ready' for reading than their typically developing peers, but the delay was more severe for the AR-Poor reader group (who were also behind the TD-Poor reader group). In addition, while the AR-Poor reader group was not significantly impaired in grammar at $\mathrm{T} 1$ it was when compared with the TD-Normal reader group at T2; arguably ongoing weaknesses in morpheme awareness tapped by our grammar task may impact literacy development more when reading and spelling material increasingly incorporates morphologically complex words.

We next examined performance on tests tapping putative endophenotypes of dyslexia, namely word/pseudoword recall and nonword repetition. Consistent with Moll et al. (2013) we found that performance on these tasks was impaired not only in atrisk readers with reading problems (AR-Poor reader) but also in unaffected peers from similar backgrounds (AR-Normal reader) at both T1 and T2. These findings confirm that phonological skills beyond phoneme awareness are risk factors for poor reading (i.e. dyslexia) (Pennington et al., 2012; Snowling \& Melby-Lervag, 2016). An unexpected finding was that the 'endophenotype pattern' was also seen for vocabulary. It should be noted however that, in contrast to Moll et al. who focused on children at family-risk of dyslexia, the at-risk group in the present study included children with oral language impairments including vocabulary deficits. An alternative explanation is that phonological skills are strongly correlated with vocabulary early in development, 
though the causal relations among these skills remain debated (e.g., Gathercole, 2006; Melby-Lervag et al., 2012).

Unlike many studies of children at-risk of dyslexia, in this study we excluded poor readers from the TD control group but retained them in the analyses to compare with the AR-Poor reader group. We found no significant difference in the severity of the reading impairment between the two groups of readers who fulfilled our criteria for reading difficulty. However, a caveat is that the AR-Poor reader group was more affected than the TD-Poor reader group and shared the putative endophenotypes of word/pseudoword recall, nonword repetition and vocabulary with the AR-Normal reader group (while the TD-Poor reader group did not). If these shared risks are indeed heritable endophenotypes of dyslexia (Bearden \& Freimer, 2006), the findings converge with evidence that there are shared genetic influences on dyslexia and language impairment (Pennington \& Bishop, 2009). They also imply that there may be more than one pathway to dyslexia.

Turning to the predictors of individual differences in literacy skills, the path model confirmed previous research showing that phoneme awareness/letter knowledge and RAN are unique longitudinal predictors of variation in early reading and spelling in Slavic languages (Caravolas et al., 2012) and extended the findings specifically to a group of children at high risk of dyslexia. In addition, the findings are consistent with research showing that RAN plays a more important role in reading fluency than in spelling (e.g., Furnes \& Samuelsson, 2011; Moll, Fussenegger, Willburger, \& Landerl, 2009; Moll et al., 2014). The model also showed that broader oral language skills are more distal predictors of these differences. The impact of oral language in preschool on later decoding in primary school was fully mediated by the three proximal code related 
skills (RAN and phoneme awareness/letter knowledge). The association between language and spelling was also fully mediated but only by two of the three proximal code related skills (phoneme awareness/letter knowledge combined as a single factor).

In summary, this is the first study of the risk factors for dyslexia in Slavic languages using a prospective approach; the findings underline the view that dyslexia is a dimensional disorder; we found no clear cut-off between children who fulfilled our criterion for poor reading and those who did not in code-related processes. The study also extends the evidence showing that difficulties in oral language development presage deficits in code-related processes that are proximal causes of dyslexia. Since there were no differences in the predictors of reading in at-risk children and controls, it could be argued that it is inappropriate to categorize children according to reading or dyslexia status. However, in educational settings such an approach has value if only some children are to be prioritized for intervention (Rose, 2009).

The present study had a number of limitations. First, the children varied considerably in age at the beginning of the study though they were all in kindergarten and had not yet received formal reading instruction. Second, we grouped together 'atrisk' children with a variety of etiologies, though on the other hand we would argue this is a valuable approach to identify cognitive risk factors shared between different disorders. Finally, since it is common practice in Slavic-speaking communities for children with language delay to be held back in kindergarten, such children had to be excluded from the present analyses because they had not received any formal reading instruction. In this light, conclusions regarding the reading outcomes of children with speech and language difficulties must remain tentative but the high-risk of dyslexia in children with an affected first degree relative is replicated. 


\section{Acknowledgements}




\section{References}

Bearden, C. E., \& Freimer, N. B. (2006). Endophenotypes for psychiatric disorders: ready for primetime? Trends in Genetics, 22, 306-313, doi: 10.1016/j.tig.2006.04.004

Bishop, D. V. (2003). Test for reception of grammar: TROG-2 version 2. Pearson Assessment.

Bishop, D. V. M., \& Snowling, M. J. (2004). Developmental dyslexia and specific language impairment: Same or different? Psychological Bulletin, 130(6), 858-886, doi: $10.1037 / 0033-2909.130 .6 .858$

Caravolas, M., Lervag, A., Mousikou, P., Efrim, C., Litavsky, M., Onochie-Quintanilla, E., .. . Hulme, C. (2012). Common patterns of prediction of literacy development in different alphabetic orthographies. Psychological Science, 23, 678-686, doi:

$10.1177 / 0956797611434536$

Caravolas, M., Mikulajová, M., \& Vencelová, L. (2008). Súbor tesov na hodnotenie pravopisných schopností pre školskú a klinickú prax. [Test battery for assessment of spelling skills for school and clinical practice]. Bratislava: Slovenská asociácia logopédov.

Caravolas, M., \& Volín, J. (2005). Battery of diagnostic tests of literacy skills for pupils in 2nd to 5th grades of primary school. Prague: IPPP.

Carroll, J. M., Mundy, I. R., \& Cunningham, A. J. (2014). The roles of family history of dyslexia, language, speech production and phonological processing in predicting literacy progress. Developmental Science, 17(5), 727-742, doi: 10.1111/Desc.12153

Gathercole, S. E. (2006). Nonword repetition and word learning: the nature of the relationship. Applied Psycholinguistics, 27, 513-543, doi: 10.1017/s0142716406060383

Hulme, C., Nash, H. M., Gooch, D., Lervag, A., \& Snowling, M. J. (2015). The Foundations of Literacy Development in Children at Familial Risk of Dyslexia. Psychological Science, 
doi: $10.1177 / 0956797615603702$

Kapalková, S., Slančová, D., Bónová, I., Kesselová, J., \& Mikulajová, M. (2010). Hodnotenie komunikačných schopností detí v ranom veku [Investigation of Communication Skills in Infants and Toddlers]. Slovenská asociácia logopédov: Bratislava.

Kessler, B., \& Caravolas, M. (2011). Weslalex: West Slavic lexicon of child-directed printed words. Retrieved from http://spell.psychology.wustl.edu/weslalex.

Landerl, K., \& Wimmer, H. (2008). Development of Word Reading Fluency and Spelling in a Consistent Orthography: An 8-Year Follow-Up. Journal of Educational Psychology, 100(1), 50-161, doi: 10.1037/0022-0663.100.1.150

Melby-Lervag, M., Lervag, A., Lyster, S. A. H., Klem, M., Hagtvet, B., \& Hulme, C. (2012). Nonword-repetition ability does not appear to be a causal influence on children's vocabulary development. Psychological Science, 23(10), 1092-1098, doi:10.1177/0956797612443833

Mistrík, J. (1993). Encyklopédia jazykovedy. Bratislava: Obzor.

Moll, K., Fussenegger, B., Willburger, E., \& Landerl, K. (2009). RAN is not a measure of orthographic processing. Evidence from the asymmetric German orthography. Scientific Studies of Reading, 13, 1-25, doi:10.1080/10888430802631684

Moll, K., Loff, A., \& Snowling, M. J. (2013). Cognitive endophenotypes of dyslexia. Scientific Studies of Reading, 00, 1-13. doi:10.1080/10888438.2012.736439

Moll, K., Ramus, F., Bartling, J., Bruder, J., Kunze, S., Neuhoff, N., .., Landerl, K. (2014). Cognitive mechanisms underlying reading and spelling development in five European orthographies. Learning and Instruction, 29, 65-77, doi:10.1016/j.learninstruc.2013.09.003

Nash, H. M., Hulme, C., Gooch, D., \& Snowling, M. J. (2013). Preschool language profiles of 
children at family risk of dyslexia: continuities with specific language impairment. Journal of Child Psychology and Psychiatry, 54(9), 958-968, doi: 10.1111/jcpp.12091

Pennington, B. F., \& Bishop, D. V. M. (2009). Relations among speech, language, and reading disorders. Annual Review of Psychology, 60, 282-306, doi:10.1146/annurev.psych.60.110707.163548

Pennington, B. F., \& Lefly, D. L. (2001). Early reading development in children at family risk for dyslexia. Child Development, 72, 816-833, doi: 10.1111/14678624.00317

Pennington, B. F., Santerre-Lemmon, L., Rosenberg, J., MacDonald, B., Boada, R., Friend, A., .. Willcutt, E. G. (2012). Individual prediction of dyslexia by single versus multiple deficit models. Journal of Abnormal Psychology, 121(1), 212, doi: 10.1037/a0025823

Puolakanaho, A., Ahonen, T., Aro, M., Eklund, K., Leppänen, P. H. T., Poikkeus, A.-M., . . . Lyytinen, H. (2007). Very early phonological and language skills: estimating individual risk of reading disability. Journal of Child Psychology and Psychiatry, 48(9), 923-931, doi: $10.1111 / \mathrm{j} .1469-7610.2007 .01763 . \mathrm{x}$

Raven, J. C. (1965). The coloured progressive matrices test. London: Lewis.

Rose, J. (2009). Identifying and teaching children and young people with dyslexia and literacy difficulties Retrieved $28^{\text {th }}$ December 2014 from http://webarchive.nationalarchives.gov.uk/20091004042342/http://www.dcsf.gov.uk/ji $\underline{\text { mroseanddyslexia/ }}$

Scarborough, H. S. (1990). Very early language deficits in dyslexic children. Child Development, 61, 1728-1743, doi: 10.2307/1130834

Snowling, M. J. (2008). Specific disorders and broader phenotypes: the case of dyslexia. Quarterly Journal of Experimental Psychology, 61, 142-156, doi: 


\section{$10.1080 / 17470210701508830$}

Snowling, M. J., Gallagher, A., \& Frith, U. (2003). Family risk of dyslexia is continuous: individual differences in the precursors of reading skill. Child Development, 74, 358373, doi: 10.1111/1467-8624.7402003

Snowling, M. J., \& Hulme, C. (2012). Annual Research Review: The nature and classification of reading disorders - a commentary on proposals for DSM-5. Journal of Child Psychology and Psychiatry, 53(5), 593-607, doi: 10.1111/j.1469-7610.2011.02495.x

Snowling, M.J., \& Melby-Lervag, M. (2016) Oral language deficits in familial dyslexia: a meta-analysis and review. Psychological Bulletin, [Epub ahead of print].

Storch, S., \& Whitehurst, G. (2002). Oral language and code-related precursors to reading: evidence from a longitudinal structural model. Developmental Psychology, 38, 934-947, doi: 10.1037//0012-1649.38.6.934

Torppa, M., Lyytinen, P., Erskine, J., Eklund, K., \& Lyytinen, H. (2010). Language Development, Literacy Skills, and Predictive Connections to Reading in Finnish Children With and Without Familial Risk for Dyslexia. Journal of Learning Disabilities, 43(4), 308-321, doi: 10.1177/0022219410369096

Torppa, M., Poikkeus, A.-M., Laakso, M.-L., Tolvanen, A., Leskinen, E., Leppanen, P. H. T., . . Lyytinen, H. (2007). Modeling the Early Paths of Phonological Awareness and Factors Supporting its Development in Children With and Without Familial Risk of Dyslexia. Scientific Studies of Reading, 11(2), 73-103, doi:

$10.1080 / 10888430709336554$

Vellutino, F. R., Fletcher, J. M., Snowling, M. J., \& Scanlon, D. M. (2004). Specific reading disability (dyslexia): what have we learned in the past four decades? Journal of Child Psychology \& Psychiatry, 45(1), 2-40, doi: 10.1046/j.0021-9630.2003.00305.x 
Wechsler, D. (2004). Wechsler Preschool \& Primary Scale of Intelligence - Third UK Edition (WPPSI-IIIUK). London: Harcourt Assessment.

Ziegler, J. C., Bertrand, D., Toth, D., Csepe, V., Reis, A., Faisca, L., . . Blomert, L. (2010). Orthographic depth and its impact on universal predictors of reading: a cross-language investigation. Psychological Science, 21(4), 551-559, doi:

$10.1177 / 0956797610363406$ 
Table 1

Mean (SD) performance of typically developing-control (TD), family risk (FR), speech-language difficulties (SLD) at T1 and T2.

\begin{tabular}{|c|c|c|c|c|c|c|c|}
\hline & & & TD & FR & SLD & $F$ group & $F$ Age \\
\hline & Time & $N$ & $M(S D)$ & $M(S D)$ & $M(S D)$ & $\left(\operatorname{partial} \eta^{2}\right)$ & $\left(\right.$ partial $\left.\eta^{2}\right)$ \\
\hline \multirow[t]{2}{*}{ Age in months } & 1 & 198 & $64.9(4.18)$ & $67.8(3.49)$ & $67.8(3.92)$ & & \\
\hline & 2 & 197 & $75.2(4.33)$ & $78.0(3.80)$ & $78.9(4.21)$ & & \\
\hline $\mathrm{NVIQ}^{1}$ & 1 & 188 & $-.08(.81)_{\mathrm{a}}$ & $.16(.95)_{\mathrm{a}}$ & $.28(.83)_{\mathrm{a}}$ & $0.880(.009)$ & $18.538(.092)^{*}$ \\
\hline \multirow[t]{2}{*}{ Phoneme Awareness ${ }^{1+}$} & 1 & 98 & $.23(.83)_{\mathrm{a}}$ & $.22(.90)_{\mathrm{a}}$ & $.06(.79)_{\mathrm{a}}$ & $0.503(.011)$ & $2.408(.025)$ \\
\hline & 2 & 193 & $.18(.84)_{\mathrm{a}}$ & $-.02(1.10)_{\mathrm{a}}$ & $-.16(.77)_{\mathrm{a}}$ & $3.119(.042)$ & $2.946(.015)$ \\
\hline \multirow[t]{2}{*}{ RAN $^{1,2}$} & 1 & 183 & $.17(.87)_{\mathrm{a}}$ & $.03(.91)_{\mathrm{a}}$ & $-.23(.90)_{\mathrm{a}}$ & $4.643(.049)$ & $2.431(.017)$ \\
\hline & 2 & 194 & $.21(.95)_{\mathrm{a}}$ & $-.13(.95)_{a b}$ & $-.22(.72)_{b}$ & $7.280(.071)^{*}$ & $5.684(.029)$ \\
\hline \multirow[t]{2}{*}{ Letter knowledge $^{1}$} & 1 & 187 & $.18(.99)_{\mathrm{a}}$ & $.33(1.11)_{\mathrm{a}}$ & $-.20(.81)_{\mathrm{a}}$ & $4.574(.048)$ & $1.969(.011)$ \\
\hline & 2 & 193 & $.22(.92)_{\mathrm{a}}$ & $.11(1.11)_{\mathrm{ab}}$ & $-.24(.88)_{b}$ & $6.451(.064)^{*}$ & $4.774(.025)$ \\
\hline \multirow[t]{2}{*}{ Word/PW Recall ${ }^{3}$} & 1 & 198 & $84.89(7.19)_{\mathrm{a}}$ & $77.02(11.46)_{b}$ & $73.21(8.80)_{b}$ & $30.007(.236)^{*}$ & $0.976(.005)$ \\
\hline & 2 & 195 & $84.23(9.71)_{\mathrm{a}}$ & $74.75(12.54)_{b}$ & $71.52(10.98)_{b}$ & $22.309(.189)^{*}$ & $1.256(.007)$ \\
\hline
\end{tabular}




$\begin{array}{lccccccc}\text { NW Repetition }^{4} & 1 & 198 & 79.15(11.66)_{\mathrm{a}} & 67.89(15.71)_{\mathrm{b}} & 65.00(14.53)_{\mathrm{b}} & 20.140(.172)^{*} & 0.165(.001) \\ & 2 & 194 & 77.21(13.23)_{\mathrm{a}} & 67.11(17.48)_{\mathrm{b}} & 66.15(13.82)_{\mathrm{b}} & 10.107(.096)^{*} & 0.770(.004) \\ \text { Vocabulary }^{5} & 1 & 195 & 18.98(7.40)_{\mathrm{a}} & 14.84(7.05)_{\mathrm{b}} & 13.88(5.75)_{\mathrm{b}} & 13.008(.120)^{*} & 2.386(.124) \\ & 2 & 191 & 24.28(6.67)_{\mathrm{a}} & 22.84(6.50)_{\mathrm{ab}} & 20.42(6.88)_{\mathrm{b}} & 5.387(.054)^{*} & 0.027(.000) \\ \text { Grammar }^{6} & 1 & 194 & 23.71(5.88)_{\mathrm{a}} & 23.42(5.43)_{\mathrm{a}} & 22.02(5.79)_{\mathrm{a}} & 3.154(.032) & 6.747(.034) \\ & 2 & 191 & 35.77(6.23)_{\mathrm{a}} & 34.61(5.85)_{\mathrm{a}} & 33.03(5.88)_{\mathrm{a}} & 4.302(.044) & 1.115(.006)\end{array}$

Note. ${ }^{1}$ composite z-score; ${ }^{2}$ items per second; ${ }^{3} \%$ correct of 56 items (T1) and max $=\%$ correct of 44 items (T2) ${ }^{4} \%$ correct of 20 items (T1) and $\%$ correct of 16 items $(\mathrm{T} 2) ;{ }^{5} \max =43 ;{ }^{6} \max =40(\mathrm{~T} 1)$ and $48(\mathrm{~T} 2)$.

Means with the same subscripts do not differ significantly after Bonferroni correction $\left(\mathrm{T} 1:^{* *} \mathrm{p}<.0063 ; \mathrm{T} 2:{ }^{* *} \mathrm{p}<.0071\right)$.

${ }^{\dagger}$ Only Czech data were used at T1 for Phoneme Awareness as Slovak data found to be unreliable. 
Table 2

Decoding Skills at T3 for the TD, FR and SLD groups, together with frequency of children fulfilling criteria for Reading Disorder.

\begin{tabular}{llll}
\hline Group & TD & FR & SLD \\
$\mathrm{N}$ & 100 & 38 & 60 \\
\hline Mean (SD) & $102.1(12.9)$ & $100.4(16.6)$ & $98.2(12.5)$ \\
$\%$ of cases $<-1.5 \mathrm{SD}$ & 12.87 & 21.62 & 20.00 \\
\hline
\end{tabular}


Table 3

Mean performance at T1 and T2 of groups classified according to decoding composite at T3.

\begin{tabular}{|c|c|c|c|c|c|c|c|c|}
\hline & & & $\mathrm{TD}$ & At-Risk & & TD & & \\
\hline & & & Poor Reader & Poor Reader & Normal Reader & Normal Reader & $\left(\right.$ Partial $\left.\eta^{2}\right)$ & $\left(\right.$ Partial $\left.\eta^{2}\right)$ \\
\hline & Time & $N$ & $M(S D)$ & $M(S D)$ & $M(S D)$ & $M(S D)$ & & \\
\hline \multirow[t]{2}{*}{ Age in months } & 1 & 198 & $64.9(3.23)$ & $68.6(2.83)$ & $67.6(3.93)$ & $64.9(4.31)$ & & \\
\hline & 2 & 197 & $75.4(4.43)$ & $78.2(4.20)$ & $79.8(3.22)$ & $74.0(3.39)$ & & \\
\hline NVIQ $^{1}$ & 1 & 174 & $-.37(.81)_{\mathrm{a}}$ & $-.38(1.01)_{\mathrm{a}}$ & $.22(.81)_{\mathrm{a}}$ & $-.04(.80)_{\mathrm{a}}$ & $2.059(.033)$ & $19.950(.098)^{* *}$ \\
\hline \multirow[t]{2}{*}{ Phoneme Awareness ${ }^{1 \dagger}$} & 1 & 98 & $-.22(.54)_{\mathrm{ab}}$ & $-.56(.46)_{b}$ & $.26(.84)_{\mathrm{ab}}$ & $.31(.85)_{\mathrm{a}}$ & $3.909(.112)^{* *}$ & $3.989(.041)$ \\
\hline & 2 & 193 & $-.68(.72)_{b c}$ & $-.91(.64)_{c}$ & $.10(.85)_{\mathrm{ab}}$ & $.30(.79)_{\mathrm{a}}$ & $17.170(.215)^{* *}$ & $4.100(.021)$ \\
\hline \multirow[t]{2}{*}{ RAN $^{1,2}$} & 1 & 171 & $-.37(.57)_{\mathrm{ab}}$ & $-.84(.69)_{b}$ & $.04(.93)_{\mathrm{ab}}$ & $.26(.88)_{\mathrm{a}}$ & $8.251(.122)^{* *}$ & $4.259(.023)$ \\
\hline & 2 & 194 & $-.48(.50)_{\mathrm{ab}}$ & $-.64(.70)_{\mathrm{b}}$ & $-.07(.81)_{\mathrm{b}}$ & $.31(.96)_{a}$ & $10.701(.145)^{* *}$ & $6.304(.032)$ \\
\hline \multirow[t]{2}{*}{ Letter Knowledge $^{1}$} & 1 & 187 & $-.43(.63)_{\mathrm{ab}}$ & $-.67(.51)_{\mathrm{b}}$ & $.16(1.03)_{\mathrm{ab}}$ & $.27(1.00)_{\mathrm{a}}$ & $6.336(.095)^{* *}$ & $3.243(.018)$ \\
\hline & 2 & 193 & $-.58(.66)_{b c}$ & $-.96(.58)_{\mathrm{c}}$ & $.11(.96)_{\mathrm{ab}}$ & $.34(.89)_{\mathrm{a}}$ & $15.453(.198)^{* *}$ & $6.146(.032)$ \\
\hline Word/PW Recall ${ }^{3}$ & 1 & 183 & $78.85(6.55)_{\mathrm{ab}}$ & $70.69(8.09)_{\mathrm{b}}$ & $76.03(10.49)_{\mathrm{b}}$ & $85.80(6.87)_{a}$ & $22.333(.258)^{* *}$ & $0.796(.004)$ \\
\hline
\end{tabular}




$\begin{array}{lcccccccc} & 2 & 195 & 82.20(9.39)_{\mathrm{ab}} & 67.95(10.16)_{\mathrm{b}} & 74.00(11.74)_{\mathrm{b}} & 84.51(9.78)_{\mathrm{a}} & 16.170(.203)^{* *} & 1.102(.006) \\ \text { NW-Rep. }^{4} & 1 & 183 & 73.85(6.50)_{\mathrm{ab}} & 62.94(9.02)_{\mathrm{b}} & 68.41(15.42)_{\mathrm{b}} & 79.94(12.07)_{\mathrm{a}} & 15.053(.190)^{* *} & 0.085(.000) \\ & 2 & 194 & 71.88(12.07)_{\mathrm{ab}} & 60.00(15.36)_{\mathrm{b}} & 68.19(14.88)_{\mathrm{b}} & 77.98(13.28)_{\mathrm{a}} & 9.289(.128)^{* *} & 0.595(.003) \\ \text { Vocabulary }^{5} & 1 & 180 & 16.85(7.48)_{\mathrm{ab}} & 11.08(5.22)_{\mathrm{b}} & 13.85(6.90)_{\mathrm{b}} & 19.30(7.38)_{\mathrm{a}} & 10.132(.138)^{* *} & 2.777(.014) \\ & 2 & 191 & 22.08(6.19)_{\mathrm{ab}} & 18.56(3.84)_{\mathrm{b}} & 22.04(7.19)_{\mathrm{ab}} & 24.59(6.72)_{\mathrm{a}} & 4.443(.067)^{* *} & 0.007(.000) \\ \text { Grammar }^{6} & 1 & 179 & 22.54(5.52)_{\mathrm{a}} & 19.67(3.37)_{\mathrm{a}} & 22.95(6.09)_{\mathrm{a}} & 23.88(5.94)_{\mathrm{a}} & 2.953(.045) & 7.227(.037) \\ & 2 & 191 & 34.17(7.22)_{\mathrm{ab}} & 30.75(5.69)_{\mathrm{b}} & 34.40(5.73)_{\mathrm{ab}} & 36.00(6.09)_{\mathrm{a}} & 4.816(.072)^{* *} & 1.452(.008)\end{array}$

Note. ${ }^{1}$ composite z-score; ${ }^{2}$ items per second; ${ }^{3} \%$ correct of 56 items (T1) and \% correct of 44 items (T2) ${ }^{4} \%$ correct of 20 items (T1) and \% correct of 16 items $(\mathrm{T} 2){ }^{5} \max =43 ;{ }^{6} \max =40(\mathrm{~T} 1)$ and $48(\mathrm{~T} 2)$.

Means with the same subscripts do not differ significantly after Bonferroni correction $\left(\mathrm{T} 1:{ }^{* *} \mathrm{p}<.0063 ; \mathrm{T} 2:{ }^{* *} \mathrm{p}<.0071\right)$.

${ }^{\dagger}$ Only Czech data were used at T1 for Phoneme Awareness as Slovak data found to be unreliable. 


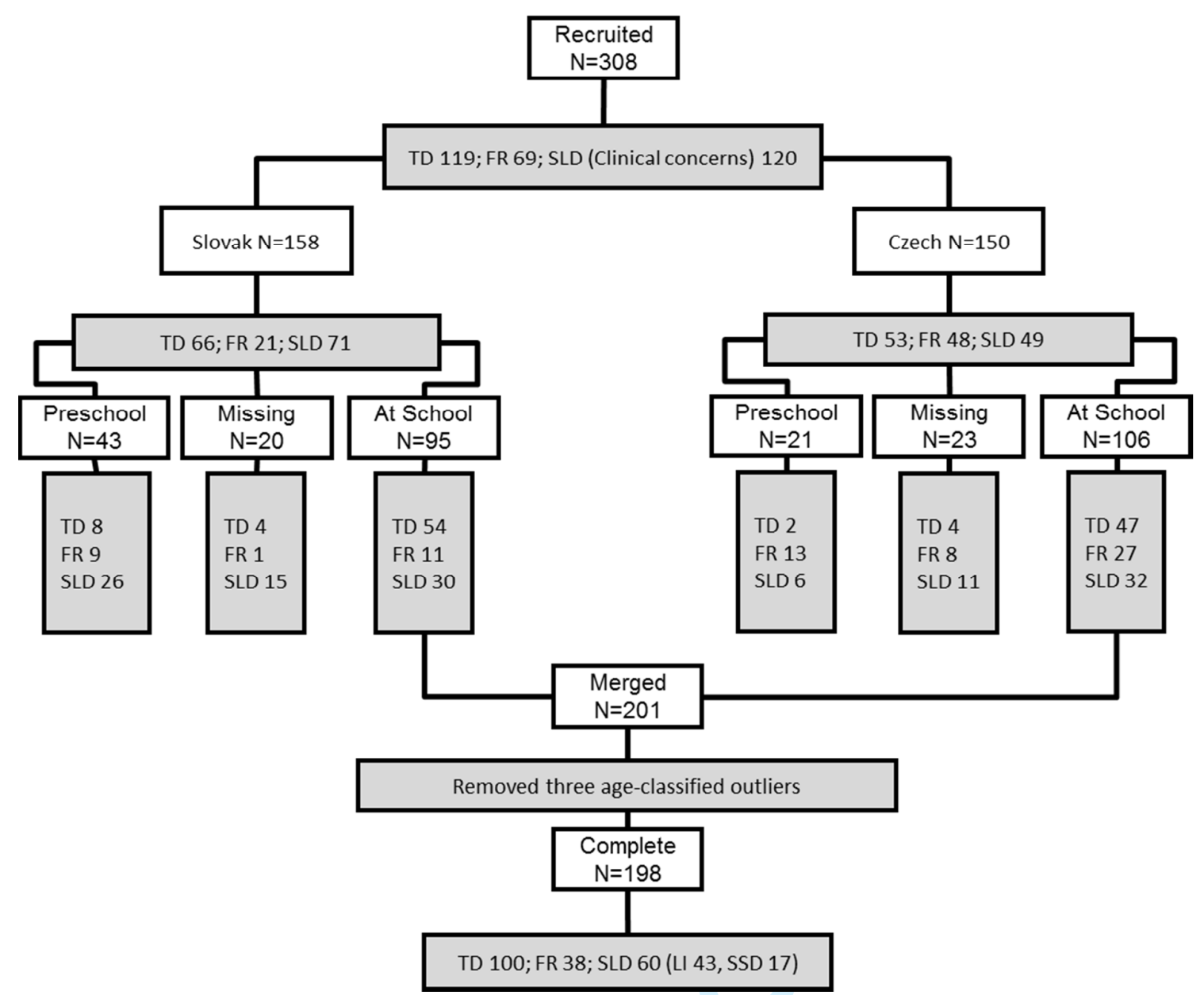

Figure 1. Frequencies of children by language, group and school status. 


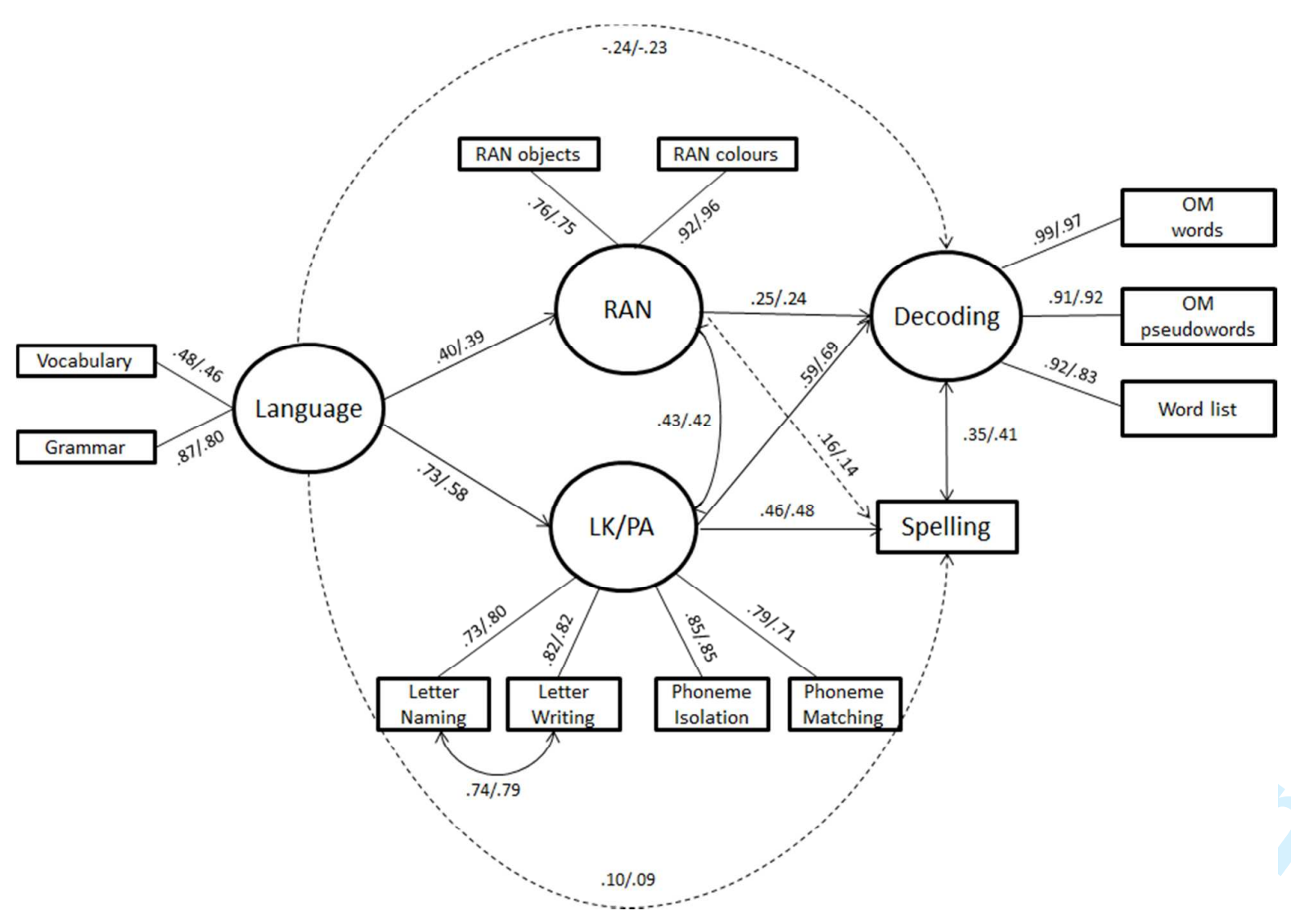

Figure 2

Path model showing the predictors of decoding and spelling in typically developing and at risk groups (paths are denoted TD/AR in diagram) 